\title{
Comparative Evaluation of Different Needle Gauge of Needle for Spinal Anesthesia in Cesarean Section for Post-Operative Complication
}

\author{
Anirudh Prasad Mandal', P.K. Gyani ${ }^{2}$, Sandeep Kumar ${ }^{3}$, Rakesh Kumar ${ }^{1}$ \\ ${ }^{1}$ Senior resident, Department of Anesthesia, GMC, Bettiah, ${ }^{2}$ Assistant Professor \& HOD, Department of Anesthesia, GMC, Bettiah, ${ }^{3}$ Junior Resident, \\ Department of Anesthesia, GMC, Bettiah.
}

\section{Abstract}

Background: Post dural Pucture headache (PDPH) Particularly Following Caesarean Section is a well-known iatrogenic complication of spinal anaesthesia mostly occours due to loss of cerebrospinal fluid (CSF) during the procedure. Aims and Objectives: The study was planned to assess comparative superiority of 27 gauze spinal needle over 25 gauze spinal needle in caesarean section for reduction of PDPH. Subjects and Methods: The study was conducted on hundred full term primi-parous women aged within 18-36 years undergoing elective Caesarean Section were selected. They were divided into two groups, receive spinal anaesthesia with 25 gauze and 27 gauze spinal needle. Results: The overall incidence of PDPH of 100 CS patients was $17 \%$ and significantly higher incidence is noticed in-group A than group B ( $26 \%$ vs $10 \%, \mathrm{p}<0.05>$ ). Attempt required to attain CSF is higher in group B and finer needle takes significantly more time to collect CSF $(\mathrm{P}<.001)$. Mean Duration for CSF Collection was 35.08 \pm 13.43 seconds (group A) and 81.12 \pm 16.71 seconds (groups B). Conclusion: Use of $27 \mathrm{G}$ spinal needle will be a good choice for reduction of PDPH.

Keywords: PDPH, Caesarean Section, spinal needle.

Corresponding Author: Dr. Rakesh Kumar, Senior Resident, Department of Anesthesia, GMC, Bettiah.

Received: July 2019

Accepted: August 2019

\section{Introduction}

Spinal anaesthesia has been widely practised for surgery below the umbilicus since its introduction by August Bier in 1898. ${ }^{[1]}$ Even with its obvious advantages, postdural puncture headache $(\mathrm{PDPH})$ remains a troublesome complication, especially in young patients, leading to patient distress and morbidity, prolonged hospital stay and increased cost. ${ }^{[2]}$ Carrie and Collins define PDPH as "a headache occurring after dural puncture and has a significant effect on the patient post-operative well-being i.e. headache which is not only postural but also continues for more than 24 hours at any level of intensity or so severe at any time that the patient is unable to maintain upright position. Factors reported to influence the incidence of PDPH are age, sex, pregnancy, previous history of $\mathrm{PDPH},{ }^{[3]}$ needle size ${ }^{[3,4]}$ needle tip shape,$^{[4,5]}$ bevel orientation to the dural fibres, ${ }^{[3,6]}$ the number of lumbar puncture attempts, ${ }^{[3]}$ midline versus lateral approach, ${ }^{[7]}$ the type of local anaesthetic solution, ${ }^{[8]}$ and clinical experience of the operator. ${ }^{[9]}$ Among these, the gauge and configuration of the needle tip seem to be of great importance Two strategies have evolved to reduce the incidence of PDPH: first, to reduce the gauge of the needle and second, to change the design of the needle tip. Studies have indicated that decreasing the needle gauge reduces the incidence of PDPH; however, it increases the technical difficulty, leading to an increase in the failure rate. ${ }^{[10-14]}$ Research aimed at altering the needle design was done as early as 1926, when Greene proposed rounding off the needle tip, which would separate rather than cut the longitudinal dural fibres. ${ }^{[15]}$ This idea was rediscovered and modified in 1952 by Hart and Whitacre, who developed a pencil-point needle that led to the current availability of smaller gauge pencil-point needles. ${ }^{[16]}$ The question is how thin a needle can be used in clinical practice to achieve the lowest incidence of PDPH without compromising success rate The aim of this prospective study was to evaluate the influence of available needle gauge on incidence of PDPH.

\section{Subjects and Methods}

This prospective study was conducted at Govt Medical College, Bettiah. The study was approved by the institutional research committee. All the participating patients were explained about the procedure and written consent was taken from the participating subjects before the commencement of the procedure. A total of 90 term parturients participated in the study.

The participating subjects aged 18-36 year, primi-para, in term, single uncompromised fetus and uncomplicated pregnancy, were included into the study. Two groups were 
0

selected and denoted Group A and Group B. The women in both group were scheduled to received spinal anesthesia for elective Cesarean section (CS) and 25 G Spinal needle were used for group A, whereas $27 \mathrm{G}$ needle were used for group B. Women were selected randomly by lottery methods where all had equal chances to enter each group. All patients were blind for the size of the needle used for spinal anesthesia Exclusion Criteria Patients refusal, Patients with abnormalities of spine, soft tissue infection at the site of needle insertion, and/or coagulation disorders were excluded. Moreover, patient's factors like history of previous CS or lumber puncture due to any cause, multiparous, pregnancy induced hypertension, required emergency CS (due to fetal distress or others), obesity (BMI>30), patients on anticoagulation therapy and concomitant respiratory tract infection or suffering from cardiovascular and neurological disorder. Before inclusion, it was assured that they did not suffer from any kind of headache disorder.

All the patients were visited a day before surgery and were described about the study, study procedure and potential benefits and risks. They were assured that procedure of this study will not enhance the chance of postdural headache other than usual headache. All patients were subjected to a thorough and detailed history of present \& past medical illness, past history of any surgical as well as anesthetic procedure along with detailed physical examination.

Preoperatively, routine investigations like Complete Blood Count (CBC), ECG, serum creatinine, random blood sugar (RBS), serum electrolytes, and chest x-ray were done in each patient. Blood pressure, heart rate and saturation estimation were done non-invasively half an hour before anesthetic procedure. Moreover, preloading by standard fluid were also done before surgery. With maintaining all aseptic precautions, spinal anesthesia procedure was performed in sitting position by the same anesthesiologist at L3-4or L4-5 intervertebral space. The patients were given a standard spinal anesthetic consisting of 10-12.5 mg (2.0-2.5 ml) of $0.5 \%$ hyperbaric Bupivacaine and $25 \mu \mathrm{g}$ Fentanyl (total volume $2.5-3 \mathrm{ml}$ ) by either a $25 \mathrm{G} \mathrm{x} 90 \mathrm{~mm}$ needle in group A, and $27 \mathrm{G} \times 90 \mathrm{~mm}$ needle in group B. Spinal needles were introduced with the needle tip bevel directed laterally following standard sterilization and subcutaneous infiltration of skin by $2 \mathrm{ml}$ of $2 \%$ lidocaine.

The women were interviewed on days 1, 2, and 3 day postoperatively and were questioned about headache. Besides the information regarding incidence, onset of headache, severity, location, and duration, were assessed respectively. PDPH was defined as by the ${ }^{6}$ headache occurring within 5 days after lumbar puncture, and being aggravated when standing or sitting and relived when lying flat' according to the definition of the International Classification of Headache Disorder, 3rd edition. Severity of headache was assessed on 1-4 scale. ${ }^{[17]}$

(1) Mild headache which permitted long periods of sitting/erect position and no other symptoms.

(2) Moderate headache, which made it difficult for the patient to stay upright for more than half an hour. It occasionally accompanied by nausea, vomiting, auditory and/or ocular symptoms.
(3) Intense headache immediately upon getting up from bed, alleviated while lying horizontal in bed. Often accompanied by nausea, vomiting, ocular and auditory symptoms and

(4) Headache that occurred even while lying horizontal in bed and greatly aggravated immediately upon standing up, eating is impossible because of nausea and vomiting. PDPH was treated with bed rest, Diclofenac $75 \mathrm{mg} / 3 \mathrm{ml}$, i.m., good hydration, paracetamol (1gm twice or thrice daily) and/or Epidural Blood Patch (EBP).

\section{Results}

Table 1: Demographic Data of Patients.

\begin{tabular}{|l|l|l|l|}
\hline Variables & Group I(n=30) & Group II $(\mathbf{n}=\mathbf{3 0})$ & P-Values \\
\hline Age $($ Years $)$ & $30.23 \pm 6.6$ & $31.34 \pm 5.6$ & $0.18^{*}$ \\
\hline Height $(\mathrm{cm})$ & $158.87 \pm 4.3$ & $158.6 \pm 4.9$ & $0.13^{*}$ \\
\hline Weight $(\mathrm{Kg})$ & $74.2 \pm 11.4$ & $73.75 \pm 10.3$ & $0.31^{*}$ \\
\hline ASA I & $21(70 \%)$ & $16(53.3 \%)$ & $0.18^{* *}$ \\
\hline ASA II & $9(30 \%)$ & $14(46.7 \%)$ & $0.18^{* *}$ \\
\hline
\end{tabular}

Table 2: Comparison of demographic and anesthetic characteristics between groups

\begin{tabular}{|c|c|c|c|}
\hline PDPH & $\begin{array}{l}\text { Group I } \\
(\mathrm{n}=45)\end{array}$ & $\begin{array}{l}\text { Group II } \\
(\mathrm{n}=45)\end{array}$ & $\begin{array}{l}\mathbf{P} \\
\text { value }\end{array}$ \\
\hline Over all PDPH & $36.7 \%$ & $6.7 \%$ & 0.005 \\
\hline $\begin{array}{l}\text { Number of lumber puncture attempts } \\
1 \text { st Attempts }\end{array}$ & $90 \%$ & $83.3 \%$ & 0.71 \\
\hline \multicolumn{3}{|c|}{ 1st Postoperative day None of the patients developed PDPH } & \multirow{11}{*}{0.036} \\
\hline 2nd Postoperative day & & & \\
\hline No Pain & $76.7 \%$ & $96.7 \%$ & \\
\hline Mild Pain & $23.3 \%$ & $3.3 \%$ & \\
\hline Moderate Pain & \multirow{2}{*}{\multicolumn{2}{|c|}{$\begin{array}{l}\text { None of the patients } \\
\text { developed } \\
\text { developed moderate to } \\
\text { severe pain }\end{array}$}} & \\
\hline Severe Pain & & & \\
\hline \multicolumn{3}{|l|}{ 3rd Postoperative day } & \\
\hline No Pain & $63.3 \%$ & $93.3 \%$ & \\
\hline Mild Pain & $23.3 \%$ & $3.3 \%$ & \\
\hline Moderate Pain & $6.7 \%$ & $3.3 \%$ & \\
\hline Severe Pain & $6.7 \%$ & $0 \%$ & \\
\hline
\end{tabular}

The demographic data of patients is shown in [Table 1]. The average age of the patients was $30.23 \pm 6.6$ years and $31.34 \pm$ 5.6 in group I and group II respectively. The average weight of the patients was $74.2 \pm 11.4 \mathrm{~kg}$ and $73.75 \pm 10.3$ in group I and group II respectively. The mean height of the patients was $158.87 \pm 4.3$ and $158.6 \pm 4.9 \mathrm{cms}$ in group I and group II respectively. There were $70 \%$ patients and $153.3 \%$ patients with ASA status I and $30 \%$ and $46.7 \%$ patients with ASA status II in group I and group II respectively. There was no statistically significant difference found in age, height, weight, and ASA status between two groups (Unpaired t test, Chi square test applied, $\mathrm{P}$-value $\geq 0.05)$. Lumber puncture was successful in first attempt in $90 \%$ and $83.3 \%$ in group I and group II respectively and no statistically significant difference was observed ( $\mathrm{p}$ value 0.71 ). Over all PDPH was observed in $36.7 \%$ and $6.7 \%$ patients in group I and group II respectively, and statistically significant difference was observed (Chi-square test $=7.95, \mathrm{df}=1, \mathrm{P}=0.005$ ) as shown in [Table 2]. As far as severity of pain was concerned, none of the patients experienced pain on first postoperative day in either group. On 2nd POD, no pain was observed in $76.7 \%$ 
and $96.7 \%$, mild pain was observed in $23.3 \%$ and $3.3 \%$ in group I and II respectively. On 3rd POD, most of the patients $63.3 \%$ and $93.3 \%$ had no pain in group I and group II respectively. Severity of PDPH was significantly high in group-I than group-II (Chi-square test $=8.56, \mathrm{df}=3, \mathrm{P}=0.036$ ).

\section{Discussion}

Spinal anesthesia is one of the most commonly used techniques in the practice of regional anesthesia. Because it is safe, economical, easy to use, needs less sophisticated equipment, cost-effective drugs, and postoperative care. Spinal anesthesia (SA) is the most popular because it preserves consciousness and respiration while providing adequate analgesia and profound muscle relaxation, ${ }^{[18]}$ hence, it is preferable over general anesthesia. However, among the side effects of SA, PDPH is the most upsetting one and results in delayed hospital discharge, increased cost, morbidity, and dissatisfaction to patient. Therefore, prevention and treatment of PDPH is of utmost importance to an anesthesiologist.

Karl August Bier, a German surgeon, first reported the PDPH in $1898 .{ }^{[19]}$ Needle tip configuration and needle gauge greatly influenced the incidence of PDPH. ${ }^{[20]}$ The $25-\mathrm{G}$ Quincke's needle has a cutting tip and the 25-G Whitacre's needle has a pencil point, non-cutting tip and might be expected to have a reduced incidence of PDPH. This randomized clinical trial was an attempt to compare the two different spinal needle tips that is Quincke's 25-G cutting tip needles and Whitacre's $25-\mathrm{G}$ non-cutting pencil point tip needles with respect to the prevalence of PDPH, attempt rate, and failure rate of successful subarachnoid block.

Frequency and severity of PDPH is directly proportional to the leakage rate of CSF through the hole in the duramater created by the spinal needle, so in high-risk patients, the use of thinner gauge needles is reasonable. Even as the incidence of PDPH is $0-2 \%$ with a $29-\mathrm{G}$ Quincke's spinal needle, the failure of subarachnoid block is common with finer gauge needles due to technical difficulties. ${ }^{[21-23]}$ Therefore, 25-G Quincke's and 25-G Whitacre's needles are in widespread use. We had chosen the 25-G spinal needles for the study because of the technical ease of insertion over the finer gauge spinal needles.

In this study, the incidence of PDPH was significantly high in cases where the $25 \mathrm{G}$ needle $(36.7 \%)$ was used compared to cases where $27 \mathrm{G}$ needle $(6.7 \%)$ was used $(\mathrm{p}<0.05)$. This is consistent with findings of other similar studies. Wadood et al. ${ }^{[25]}$ reported an incidence of $30.0 \%$ in $25 \mathrm{G}$ needle group compared to $14.0 \%$ in $27 \mathrm{G}$ needle group. Onset, site, severity and duration of headache varied across studies involving comparison of different size needles. ${ }^{[24]}$

Most of them reported minor and statistically non-significant differences across comparisons groups. This implies that these variable did not differ much with use of different needles. Number of trials for a successful needle prick was found high in $27 \mathrm{G}$ spinal needle groups. $17 \%$ percent patients in this group required more than one trial. Whereas, patients in $25 \mathrm{G}$ group required multiple trials in $10 \%$ cases. Time to get CSF fluid was also found to be statistically significantly higher in group B $(27 \mathrm{G})$ compared to group A
(25G). These findings, supported by other studies, indicate that small bore needles, although lowers the incidence of PDPH, have high failure rate, takes longer time to get CSF and prolongs anesthetic injection times. These could be attributed to decreased internal diameter of the more fine needles which provide increased resistance to CSF fluid as well as local anesthetic agents.

Pencil point needles are considered to produce less damage to the dural fibers and allow the hole to close more readily. Thus they have a lower incidence of post dural puncture headache than cutting needle tip designs. The overall incidence of postdural puncture headache ranges from $0 \%$ to $37 \%$ as reported by various authors. Reported frequency of PDPH ranges from $4 \%$ to $40 \%$ when $25 \mathrm{G}$ Quincke spinal needle is used in young females. Ross et al. Reported PDPH in 9\% of patients. In the study by Roheena and colleagues, severity of PDPH was from mild to moderate. None of the patients complained of severe PDPH. It was more on the 1st postoperative day and gradually decreased on the subsequent days. Incidence of PDPH with 27 gauge Quincke needle ranges from $1.1 \%$ to $12.8 \%$. However, in a recent study by Muhammad, et al., frequency of PDPH was $0 \%$ with $27 \mathrm{G}$ Quincke spinal needle when spinalanaethesia was administered for Caesarean section. In a study by Viitanenet, al., PDPH incidence was $8.5 \%$. It was mild in $4 \%$, moderate in $3 \%$ and severe in $1 \%$ of patients. Symptoms started on first or second day after spinal injection and lasted for 3 days. Our study, therefore, clearly demonstrated a significant reduction in frequency of PDPH when 27G Quincke spinal needle was used as compared to $25 \mathrm{G}$ Quincke spinal needles. However, a study by Shah and colleagues, which closely resembles our study, demonstrated PDPH incidence of $20 \%$, and $12.5 \%$ patients with 25G Quincke, and 27G Quincke needles respectively. Although frequency of PDPH was relatively higher in all the three groups in that study, it was again clearly observed that $27 \mathrm{G}$ Whitacre needle reduced the frequency of PDPH in patients undergoing Caesarean section. There also not taken into account whether the patient had any other medical problem causing headache.

\section{Conclusion}

Although PDPH is a self-limiting and nonfatal condition, its postural nature prevents the patient from performing routine activity and many make them anxious and depressed. Therefore these patients require psychological support and a lot of reassurance in addition to therapeutic measures. Preventive measures like smaller needle size, shape of needles and direction of needle bevel in relation to dural fibers, should always be considered with the hope to decrease the incidence of PDPH. Overall, we concluded that when performing spinal anaesthesia for Caesarean section, 27G Quincke spinal needle has definite advantage over 25G Quincke spinal needles as far as frequency and severity of PDPH is concerned. Therefore we recommend routine use of the $27 \mathrm{G}$ Quincke spinal needle when performing spinal anaesthesia for Caesarean section. 
0

\section{References}

1. Wulf HFW. The centennial of spinal anesthesia. Anesthesiology 1998;89:500-6.

2. Lybecker H, Djernes M, Schmidt JF. Postdural puncture headache. Acta Anaesthesiol Scand 1995;39:605-12.

3. Lybecker H, Moller JT, May O, Nielsen HK. Incidence and prediction of post dural puncture headache: a prospective study of 1021 spinal anesthesias. Anesth Analg 1990;70:389-94.

4. Halpern S, Preston R. Postdural puncture headache and spinal needle design - metaanalyses. Anesth 1994;81:1376-83.

5. Ross BK, Chadwick HS, Mancuso JJ, Benedetti C. Sprotte needle for obstetric anesthesia: decreased incidence of postdural puncture headache. Reg Anesth 1992;17:29-33.

6. Tarkkila PJ, Heine H, Tervo RR. Comparison of Sprotte and Quincke needles with respect to post dural puncture headache and backache. Reg Anesth 1992;17:283-7.

7. Janik R, Dick W. Post spinal headache: its incidence following the median and paramedian techniques. Anaesthesist 1992;41:137-41.

8. Naulty JS, Hertwig L, Hunt CO, et al. In uence of local anesthetic solution on postdural puncture headache. Anesthesiology 1990;72:450-

9. Shnider SM, Levinson G. Anesthesia for cesarean section. In: Shnider SM, Levinson G eds. Anesthesia for obstetrics. 2nd edition. Baltimore: Williams \& Wilkins, 1987;159-78.

10. Shutt LE, Valentine SJ, Wee MYK, et al. Spinal anaesthesia for Caesarean section: comparison of 22-gauge and 25-gauge Whitacre needles with 26-gauge Quincke needles. Br J Anaesth 1992;69:589-94.

11. Lynch J, Arhelger S, Krings EI. Post-dural puncture headache in young orthopaedic in patients: comparison of a $0.33 \mathrm{~mm}$ (29-gauge) Quincketype with a $0.7 \mathrm{~mm}$ (22-gauge) Whitacre spinal needle in 200 patients. Acta Anaesthesiol Scand 1992;36:58-61.

12. Tarkkila PJ. Incidence and causes of failed spinal anesthetics in a university hospital: a prospective study. Reg Anesth 1991;16:48-51.

13. Lynch J, Kasper SM, Strick K, et al. The use of Quincke and Whitacre 27-gauge needles in orthopedic patients: incidence of failed spinal anesthesia and postdural puncture headache. Anesth Anals 1994;79:124-8.
14. Sayeed YG, Sosis M, Braverman B, Ivankovich AD. An in vitro investigation of the relationship between spinal needle design and failed spinal anesthesia. Reg Anesth 1993;18:85.

15. Greene HM. Lumbar puncture and the prevention of post puncture headache. JAMA 1926;86:391-2.

16. Hart J, Whitacre R. Pencil-point needles in the prevention of post-spinal headache. JAMA 1951;147:657-8.

17. Mohammed EL, El-Shal SM. Efficacy of different size Quincke spinal needles in reduction of incidence of Post-Dural Puncture Headache (PDPH) in Caesarean Section (CS). Randomized controlled study. Egyptian Journal of Anaesthesia. 2017; 33:53-58.

18. Gonano C, Leitgeb U, Sitzwohl C, Ihra G, Weinstabl C, Kettner SC. Spinal Versus General Anaesthesia for Orthopedic Surgery: Anaesthesia Drug and Supply Costs. Anesth Analg 2006;102:524-9.

19. Pal A, Acharya A, Pal ND, Dawn S, Biswas J. Do pencil-point spinal needles decrease the incidence of postdural puncture headache in reality? A comparative study between pencil-point $25 \mathrm{G}$ Whitacre and cutting-beveled $25 \mathrm{G}$ Quincke spinal needles in 320 obstetric patients. Anesth Essays Res 2011;5:162-6.

20. Dittmann M, Schafer HG, Ulrich J, Bond-Taylor W. Anatomical reevaluation of lumbar dura mater with regard to postspinal headache. Effects of dural puncture. Anaesthesia 1988;43:635-7.

21. Flaatten H, Rodt SA, Vamnes J, Rosland J, Wisborg T, Koller ME. Postdural puncture headache. A comparison between 26 and 29 gauge needles in young patients. Anesthesia 1989;44:147-9.

22. Lesser P, Bembridge M, Lyons G, MacDonald R. An evaluation of 30 gauge needle for spinal anesthesia for Cesarean section. Anesthesia 1990:45:767-8.

23. Geurts JW, Haanschoten MC, Van Wijk RM, Kraak H, Besse TC. Postdural puncture headache in young patients. A comparative study between the use of $0.52 \mathrm{~mm}$ ( 25 gauge) and $0.33 \mathrm{~mm}$ ( 29 gauge) spinal needles. Acta Anesthesiol Scand 1999;34:350-3.

24. Evans RW. Complications of lumbar puncture. Neurol. Clin. 1998; 16:83-105.Vandam LD, Dripps RD. Long term follow-up of patients who received 10,098 spinal anesthetics. Syndrome of decreased intracranial pressure (headache, ocular and auditory difficulties)". J Am Med Assoc 1956; 161:586-91.

Copyright: () the author(s), publisher. Academia Anesthesiologica International is an Official Publication of "Society for Health Care \& Research Development". It is an open-access article distributed under the terms of the Creative Commons Attribution Non-Commercial License, which permits unrestricted non-commercial use, distribution, and reproduction in any medium, provided the original work is properly cited.

How to cite this article: Mandal AP, Gyani PK, Kumar S, Kumar R. Comparative Evaluation of Different Needle Gauge of Needle for Spinal Anesthesia in Cesarean Section for Post-Operative Complication. Acad. Anesthesiol. Int. 2019;4(2):118-121.

DOI: dx.doi.org/10.21276/aan.2019.4.2.28

Source of Support: Nil, Conflict of Interest: None declared 